\title{
FORMULÁRIO PARA COMUNICAÇÃO DIÁRIA DE ENFERMAGEM EM UNIDADES HOSPITALARES: VALIDAÇÃO DE UM INSTRUMENTO
}

\author{
Daily report for nursing communication in internment hospital \\ units: validating an instrument.
Formulario para comunicación diária de enfermaria en unidades hopitalares de internación: Validación de un instrumento.

\section{RESUMO}

Estudo descritivo com o objetivo de validar o conteúdo do instrumento Registro Diário da Unidade, que se propõe a registrar informações relacionadas à movimentação e perfil de pacientes, recursos humanos, procedimentos, pendências e intercorrências de cada turno. Foi realizado em um hospital do interior de São Paulo. Avaliado pelos juízes, especialistas na área, obteve um nível de concordância acima de $70 \%$, sendo disponibilizado nas unidades durante os 30 dias do mês de junho. Foi novamente analisado e reformulado. Concluiu-se que o instrumento foi validado quanto ao seu conteúdo por não apresentar discordância significativa na avaliação dos juízes. Com isso sugere-se um novo estudo para avaliar a aplicabilidade do instrumento validado.

Palavras-chave: Comunicação. Enfermagem. Controle de Formulários e Registros.

\begin{abstract}
Descriptive study targeting the validation of the instrument called "Registro Diário da Unidade" (Unit Daily Report) contents, which proposal is register information about patients' "flow" and profiles, human resources, procedures, left items and abnormal occurrences in each shift. The study has taken place in a School Hospital into the state of Sao Paulo. It has also been valuated by judges, specialists in this area with accordance higher than $70 \%$. Than, has been used in every unit of this hospital during 30 days in June of 2007. After this, have been reanalyzed and reformulated. Conclusions: the instrument is validated by its contents for not representing judge's discordance. The next step is now to apply a new study to check its applicability.
\end{abstract}

Keywords: Communication. Nursing. Forms and Records Control

\section{Resumen}

Estudio descriptivo con objetivo de validar el contenido del instrumento "Registro Diario de la Unidad", para registrar informaciones relacionadas a la movimentación y el perfil de los pacientes, de las personas que trabajan en ello, los procedimientos, las cosas pendientes (que necesitan ser hechas) y las que se pasan a los turnos. Fue realizado en un hospital de enseñanza del interior de la provincia de São Paulo. Avaliado por jueces, expertos, ha logrado un nivel de concordancia superior a 70\%, y utilizado en las unidades durante los treinta dias del mes de junio; despues fue otra vez analisado y reformado. Se ha concluido que el instrumento fue apreciado por su contenido, por no tener discordancia significativa en la avaluación de los juices. Por ello, ha la sugerencia de hacer un nuevo estúdio para avaliar la aplicabilidad del instrumento validado. 


\section{INTRODUCÃO}

As transformações sócio-político-econômicas que vivenciamos são decorrência do capitalismo, da crescente globalização e do avanço da tecnologia. Tais fenômenos têm impulsionado as organizações e as pessoas à busca da qualidade, tornando-as mais eficazes, mais competitivas, mais humanas e mais úteis à sociedade como um todo.

Já em 1993, Martinelli refere que os custos na área hospitalar se elevaram até níveis insuportáveis a qualquer fonte pagadora e somente a melhoria da produtividade pode gerar soluções ${ }^{1}$. Neste cenário, devido ao crescimento dos gastos com a atenção à saúde, aconteceu uma expansão dos estudos voltados para novas propostas metodológicas sobre avaliação dos serviços de saúde e, em particular, sobre a qualidade e os custos desta atenção.

Como nova abordagem da administração, a qualidade é marcada por princípios, idéias e crenças que buscam, em última instância, a satisfação dos clientes, dos trabalhadores, dos fornecedores e acionistas ${ }^{2}$. 0 gerenciamento da qualidade (Total Quality Management-TQM) é o processo através do qual se busca implantar a filosofia da qualidade total, cuja principal finalidade é a melhoria contínua dos produtos ou serviços, pelo aprimoramento do trabalho dos diversos membros e de todas as áreas da organização. Ele utiliza conceitos da moderna administração, envolvimento e comprometimento das pessoas, introdução de inovações por sugestões e instrumentos de medida e de avaliação do trabalho, buscando a redução do desperdício pela utilização adequada dos recursos e 0 atendimento das necessidades do cliente pela melhoria dos processos de trabalho ${ }^{3}$.

Brocka \& Brocka ainda acrescentam que este processo inclui a integração de todos no ambiente da organização: empregados, fornecedores e usuários. Diz que ele se baseia em dois princípios: primeiro, é um processo controlável e não acidental; segundo, ele é uma capacidade inerente aos empregados? ${ }^{2}$.

A gerência subsidiada na informação é mais que uma necessidade, uma nova filosofia mundial de trabalho. Os avanços na organização da assistência serão baseados, cada vez mais, em uma informação descentralizada e disponível, propiciando aos trabalhadores a melhoria de seu processo de trabalho e à sociedade a possibilidade de entendimento e controle através de suas organizações ${ }^{4}$.

A comunicação faz parte de todos os relacionamentos pessoais e de todas as atividades do homem, fornecendo os meios através dos quais as pessoas podem viver e trabalhar juntas. É um dos mais importantes instrumentos de enfermagem e influencia diretamente a qualidade da assistência que prestamos ao indivíduo. É indispensável no processo de liderança, pois através dela o enfermeiro transfere e recebe conhecimentos, organiza seu serviço e traça objetivos a serem atingidos juntamente com sua equipe ${ }^{5}$. Dentro do trabalho na saúde, o processo informacional, que pressupõe o uso da comunicação, é, talvez, uma das mais importantes ferramentas que se interpõem entre o trabalhador e o "ser cuidado", uma vez que este não é algo inanimado, sem emoções, sem cultura, sem estímulos: é sujeito ${ }^{6}$.

A comunicação é um dos temas mais pesquisados em Enfermagem devido à sua complexidade, à importância que tem na qualidade da assistência e por se relacionar direta ou indiretamente com todas as ações de cuidado do enfermeiro ${ }^{7}$. Dada sua importância e a preocupação crescente com esse assunto, o XXVIII Congresso Brasileiro de Enfermagem, em 1976, discutiu "Sistemas de Registros de Enfermagem" como um de seus temas oficiais. Posteriormente, em 1988, houve o I Simpósio Brasileiro de Comunicação em Enfermagem, evento que acontece até os dias de hoje.

Pode-se traçar a origem das preocupações com a qualidade às próprias origens da Enfermagem, tendo como marco os trabalhos de Florence Nightingale, a matriarca da profissão. Durante a guerra da Criméia, Nightingale visitava os hospitais que tratavam os feridos e começou a observar diferenças no número de mortes que ocorriam em cada um deles e que não se relacionavam necessariamente com a gravidade dos ferimentos. Graças a estas observações os hospitais passaram a manter registros organizados de seus feridos e uma série de medidas de organização, higiene e assepsia passaram a ser adotadas com evidente melhoria da situação ${ }^{8}$.

Diante do exposto e da vivência profissional, sente-se a necessidade de registrar a rotina diária da enfermagem em unidades de internação. Para isto, decidiu-se monitorizar dados que possam embasar a tomada de decisão acerca da estrutura do serviço. Compreende-se estrutura, conforme Donabedian ${ }^{9}$, "como características relativamente estáveis que proporcionam a assistência, dos instrumentos e recursos existentes a disposição, assim como os aspectos físicos e organizacionais. Este componente inclui os recursos humanos, físicos, materiais e financeiros, assim como os sistemas de informação e os instrumentos normativos que são necessários para a implementação da assistência à saúde."

Considerando a comunicação um instrumento de registro de informação da enfermagem, o objetivo deste trabalho foi elaborar e validar o instrumento Registro Diário da Unidade, proposto como uma forma de comunicação escrita onde ficarão registradas informações acerca da unidade, dos recursos profissionais, pacientes, procedimentos realizados, intercorrências e pendências, contribuindo assim para documentar e conhecer melhor a realidade diária dos profissionais de enfermagem das unidades onde for aplicado.

\section{OBJETIVOS}

a) Realizar a validação de conteúdo do instrumento

Registro Diário da Unidade;

b) Aplicar o instrumento por 30 dias;

c) Avaliar os resultados obtidos;

d) Elaborar a versão final do instrumento. 


\section{SUJEITOS E MÉTODOS}

\section{Local do estudo}

0 estudo foi desenvolvido em um hospital de ensino no interior do Estado de São Paulo, nas unidades de Terapia Intensiva (UTI), Emergência Clínica e Cirurgia do Trauma (EC/ CT).

As unidades estudadas apresentam as seguintes características: na Unidade de Terapia Intensiva há 26 leitos, sendo 12 para pacientes em pós-operatório imediato, 8 leitos de UTI geral para atender pacientes transferidos de outras unidades, incluindo outras instituições, e 6 leitos na Unidade Coronariana para pacientes com afecções cardiovasculares. 0 quadro de funcionários desta unidade é constituído por 1 diretor de enfermagem, 3 supervisores, 41 enfermeiros, 56 técnicos e 2 auxiliares de enfermagem.

A unidade de internação de Emergência Clínica, responsável pelo atendimento a pacientes clínicos provenientes do ProntoSocorro (PS) e de outras unidades e instituições, possui 14 leitos, sendo 6 para pacientes com cuidados intensivos e 8 para cuidados semi-intensivos.

A Cirurgia do Trauma, responsável pelo atendimento a pacientes com patologias cirúrgicas de urgência e eletivas, tanto traumáticas quanto não-traumáticas, possui 16 leitos, sendo 4 para pacientes em cuidados intensivos e $12 \mathrm{em}$ cuidados semi-intensivos.

0 quadro de funcionários compreende 1 diretor, 3 supervisores, 23 enfermeiros, 48 técnicos e 4 auxiliares de enfermagem.

\section{Delineamento do estudo}

0 estudo é do tipo descritivo, sem intervenções diretas com o paciente.

Foi dividido em três etapas: Primeira Etapa - elaboração e avaliação do instrumento por juízes; Segunda Etapa - aplicação do instrumento por 30 dias; Terceira Etapa - elaboração da versão final do instrumento.

\section{Primeira Etapa}

0 instrumento foi enviado a cinco juízes, tendo como critério a formação de enfermeiro, experiência com o tema comunicação na enfermagem, validação de instrumento e/ou experiência assistencial. Os quatro respondentes foram: a) doutor em Enfermagem docente de universidade pública estadual com vários trabalhos desenvolvidos na área de comunicação em Enfermagem, b) docente de universidade privada e enfermeiro assistencial com trabalhos na área de desenvolvimento e validação de instrumentos c) docente de universidade privada e enfermeiro assistencial com trabalhos na área de elaboração de protocolos e relações humanas d) enfermeiro assistencial e especialista de unidade de terapia intensiva. As alterações sugeridas foram acatadas quando indicadas por pelo menos metade dos juízes.

\section{Segunda Etapa}

Fizeram parte da amostra os enfermeiros que atenderam os seguintes critérios de inclusão: exercer atividades de assistência nas referidas unidades e consentir em participar do estudo. Como critérios de exclusão, foram consideradas ausências por motivo de férias ou licença médica, durante todo o período de orientação e coleta de dados.

Todos os 64 enfermeiros lotados nessas unidades foram convidados a participar do estudo. Foram excluídos sete profissionais: cinco estavam em período de férias ou licença médica durante o treinamento para explicação do preenchimento do instrumento e dois não concordaram em participar. Assim, 57 enfermeiros foram orientados e participaram da pesquisa, assinando o termo de consentimento livre e esclarecido.

\section{Terceira Etapa}

Esta etapa constou da elaboração da versão final do instrumento. Com base nos resultados da aplicação e nas sugestões feitas pelos enfermeiros, o instrumento foi alterado e disponibilizado a dois juízes, tomando assim sua versão final (Apêndice A).

\section{Instrumentos de coleta de dados}

0 instrumento elaborado pelos pesquisadores se propõe a registrar o panorama diário da unidade onde for aplicado. Para isso, registra a movimentação de pacientes, os recursos humanos de enfermagem disponíveis, os procedimentos realizados, o perfil de paciente, as pendências e intercorrências de cada turno de trabalho. Elaborou-se, também, um roteiro de preenchimento com a finalidade de explicar todos os itens seguindo a seqüência dos conjuntos de dados apresentados, ambos submetidos à avaliação dos juízes e à aplicação.

Na sua primeira versão, era intitulado "Formulário para passagem de plantão", porém, acatando sugestões dos juízes sobre a inadequação do nome dado e em acordo com os mesmos, o instrumento passou a ser chamado "Registro diário da unidade".

\section{Coleta de dados}

Os enfermeiros, sujeitos do estudo, foram abordados individualmente pela pesquisadora e foram orientados quanto ao preenchimento do instrumento. Concomitantemente, foram orientados quanto aos aspectos éticos do estudo e foi solicitada a assinatura do Termo de Consentimento Livre e Esclarecido. Cada unidade ficou de posse de um livreto com um roteiro de preenchimento do registro e impressos em quantidade suficiente para os 30 dias de aplicação do instrumento

\section{Aspectos éticos da pesquisa}

0 projeto de pesquisa recebeu parecer favorável do Comitê de Ética em Pesquisa (CEP) da Faculdade de Ciências Médicas da UNICAMP sob $n^{\circ}$ 519/2005, homologado na reunião ordinária do CEP/FCM em 12/09/2005. Não houve risco ou prejuízo para os participantes do estudo, tendo em vista que os sujeitos apenas fizeram os registros de sua rotina de trabalho nas unidades. 


\section{Tratamento dos dados}

Os dados foram submetidos à análise estatística descritiva, com o uso do programa Microsoft Excel $®$.

\section{RESULTADOS}

\section{Análise dos juízes: validação de conteúdo}

Os resultados das avaliações dos juízes em relação ao instrumento apresentaram um nível de concordância acima de 70\%. Os itens de discordância são descritos a seguir:

- Nome do instrumento:

0 nome do instrumento foi considerado inadequado por $75 \%$ dos juízes. Seguindo suas sugestões, foi adotado o nome "Registro diário da unidade".

- Censo:

0 instrumento contém uma parte destinada ao censo de pacientes, onde originalmente se mencionavam duas unidades e havia uma linha destinada ao registro de outras unidades de procedência. Seguindo a opinião de $75 \%$ dos juízes, foram acrescentadas outras unidades além das já mencionadas.

- Procedimentos:

Dos juízes, $50 \%$ observaram que não havia solicitação quanto ao registro de curativos. A este item foi acrescentada a descrição de seis tipos de curativos.

Quanto à classificação do quesito radiografias realizadas, este foi questionado por $50 \%$ dos juízes e passou a ser incluído no item procedimentos; a alteração foi realizada e foi delimitado o local conforme sugestão. Além disso, este quesito passou a ser chamado "Rx realizados na unidade".

0 quesito "passagem de cateter venoso profundo" foi observado por $25 \%$ dos juízes, quanto à sua clareza, e foi sugerida a descrição dos tipos de cateter. Mesmo com 25\% dos juízes, a observação foi acatada graças à sua pertinência, e foram descritos os tipos de cateter que o instrumento pretendia mensurar.

- Perfil do paciente:

0 instrumento apresenta um tópico em que se pede que sejam anotados o número de drogas vasoativas sendo administradas na unidade e o número de pacientes que as estejam recebendo. Metade dos juízes considerou necessária mais clareza com o que se pretendia neste quesito. Ele foi mantido, mas a orientação quanto ao seu preenchimento foi mais detalhada, havendo acréscimo de exemplos.

- Pendências e intercorrências:

Para $75 \%$ dos juízes os tópicos deveriam ser descritos com subitens. Essa sugestão foi aceita e foram descritos quatro subitens para pendências e sete para intercorrências.

- Organização e o desenho do instrumento:

Houve $75 \%$ de discordância entre os juízes. Acatando suas sugestões, foram feitas correções ortográficas, identificação de tópicos e subitens, e o instrumento passou a ocupar os dois lados da folha.

\section{Aplicabilidade do instrumento}

Dos 64 (100\%) profissionais que compuseram a população total do estudo, obteve-se uma amostra de 57 (89\%) enfermeiros que participaram do estudo.

Pode-se observar a distribuição do número e percentuais de enfermeiros que participaram do estudo em relação ao turno de trabalho na Tabela 1.
Tabela 1 - Freqüência absoluta e relativa de enfermeiros que participaram do estudo, em relação ao turno de trabalho. Campinas, 2006.

\begin{tabular}{lcccl}
\hline Unidades & Manhä & Tarde & Moite & Total \\
\hline UTl & 11 & 9 & 18 & $38(67 \%)$ \\
EC(CT & 5 & 5 & 9 & $19(33 \%)$ \\
Total & $16(28 \%)$ & $14(25 \%)$ & $27(47 \%)$ & $57(100,00 \%)$ \\
\hline
\end{tabular}

0 instrumento esteve disponível nas unidades pelo período de 30 dias. Na Tabela 2 observamos o total de dias mensurados e o número de instrumentos preenchidos por turno de trabalho.

Foram considerados todos os instrumentos preenchidos. Do total de 210 instrumentos que deveriam ser mensurados, foram preenchidos 192, considerando aqui que pelo menos um turno tenha utilizado o instrumento. 0 instrumento foi aplicado em $91 \%$ dos dias que nos propusemos a mensurar.

Tabela 2 - Total de dias mensurados (T) e do número de instrumentos preenchidos por turno de trabalho. Campinas, 2006.

\begin{tabular}{|c|c|c|c|c|}
\hline \multirow[t]{2}{*}{ Unidades } & \multirow[t]{2}{*}{ T } & \multicolumn{3}{|c|}{ Instrumentos preenchidos } \\
\hline & & Manhã & Tarde & Noite \\
\hline UTI 201 & $26(100 \%)$ & $20(77 \%)$ & $19(73 \%)$ & $19(73 \%)$ \\
\hline UTI 203 & $24(100 \%)$ & $21(88 \%)$ & $22(91 \%)$ & $15(63 \%)$ \\
\hline UTI 205 & $28(100 \%)$ & $21(75 \%)$ & $14(50 \%)$ & $16(57 \%)$ \\
\hline UT| 301 & $30(100 \%)$ & $26(87 \%)$ & $25(83 \%)$ & $18(60 \%)$ \\
\hline UT| 303 & $29(100 \%)$ & $29(100 \%)$ & $24(83 \%)$ & $21(72 \%)$ \\
\hline $\mathrm{EC}$ & $26(100 \%)$ & $24(92 \%)$ & $7(27 \%)$ & $19(73 \%)$ \\
\hline CT & $29(100 \%)$ & $25(86 \%)$ & $26(90 \%)$ & $22(76 \%)$ \\
\hline
\end{tabular}

\section{Aplicação}

Após aplicação do instrumento por 30 dias foram identificados alguns itens, apresentados a seguir, em que mudanças eram necessárias.

No censo, por sugestão dos juízes, havia sido incluída a unidade de procedência dos pacientes admitidos. Entretanto, este item não foi preenchido por vários enfermeiros, o que levou a ser retirado da versão final. Além disso, os dados obtidos demonstraram uma característica pré-definida de procedência relacionada ao tipo de unidade [p.ex., na unidade de pósoperatório (UP0), 94\% pacientes procedem CC].

No tópico relativo a procedimentos, não houve descrição em nenhum dos turnos dos itens j, k e l. Considerou-se que mesmo sendo a inclusão destes parte da sugestão de um dos juízes, ele poderia ser descrito no quesito "outros", devido à sua não-ocorrência no período de aplicação.

No quesito "mudança de decúbito realizada", observouse, em vários turnos, a indicação do número de pacientes que necessitavam de mudança de decúbito, e não o número de mudanças realizadas. Diante disto conclui-se que o item gerou 
duplicidade de informação, o que, justifica sua retirada do instrumento, já que o dado coletado não seria fidedigno.

0 quesito "coleta de sangue para exames" foi subdividido na versão final em "coleta de gasometria" e "coleta de sangue para exames", devido à coleta de um grande número de gasometrias nas unidades pesquisadas.

Já no quesito "outros", os itens mais descritos pelos enfermeiros e acrescidos à versão final foram: Higiene oral, ECG, Colocar paciente em poltrona, Retornar paciente ao leito, Curativo de Peritoneostomia e Troca de roupa de cama.

No tópico "perfil de pacientes", puderam-se observar na aplicação do instrumento algumas duplicidades de informação comparando os dados descritos e os turnos. Por isso decidiu-se reformular os quesitos de forma a agrupar e explicar melhor os subitens.

0 quesito "cateter swan-ganz" foi retirado devido à baixa incidência, e "peritoneostomia" foi transferido para procedimentos devido à sua grande ocorrência de descrição em procedimentos.

No quesito "outros" foram considerados e acrescidos: AA (ar ambiente), Dieta VO assistida, FAD 100 (Hemolenta), Isolamento.

Foram retiradas diversas siglas, passando a constar: Isolamento, Entubados, Traqueostomizados, Ar ambiente, Ventilação mecânica invasiva, Ventilação mecânica nãoinvasiva, Suporte de $\mathrm{O}_{2}$, Sedados, $\mathrm{N}^{0}$ de pacientes em uso droga vasoativa, Hemodiálise convencional, Hemolenta, Irrigação, Dieta VO assistida, Nutrição enteral, Nutrição parenteral, Mobilização em bloco, Outros.

Quanto ao tópico "pendências", todos os quesitos apresentados foram mensurados, por isso foram mantidos.

No tópico "intercorrências" foi apontada pelo menos uma intercorrência em cada quesito, sendo acrescidos os seguintes quesitos à versão final:

- Quebra equipamento: Cama e Bomba de infusão.

- Falta equipamento: Esfignomanômetro, Estetoscópio, Monitor, Sensor $\mathrm{O}_{2}$.

- Falta material unidade respiratória: Máscara de ambu, Umidificador e Nebulizador.

- Falta material almoxarifado; foram agrupados devido à maior ocorrência das descrições: Agulha, Seringa, Luva procedimento, Luva estéril, Máscara, Tira reagente.

0 item "falta material lavanderia" foi incluído com os seguintes quesitos: Lençol, Fralda pano, Fralda descartável e Outros.

\section{DISCUSSÃO}

A busca por qualidade na assistência à saúde tem sido objetivo comum em vários países do mundo, tendo como desafio oferecer a melhor assistência a um maior contingente de pessoas, por um menor custo.

Em vista dos fatores envolvidos no gerenciamento da qualidade, a fim de atender às exigências atuais de mercado, Feigenbaum ${ }^{10}$ considera essencial que organizações tenham um sistema definido e bem estruturado que identifique, documente, coordene e mantenha todas as atividades-chave necessárias para garantir as indispensáveis ações na qualidade ao longo de todas as operações relevantes. 0 autor define sistema de qualidade como "a combinação da estrutura operacional ampla documentada segundo procedimentos técnicos e gerenciais integrados e efetivos, guiando ações coordenadas de pessoas, máquinas e dados da empresa através de meios mais práticos e adequados e, assegurando ao cliente satisfação quanto à qualidade e seus custos". Sistema de gestão refere-se a tudo o que a organização faz para gerenciar seus processos ou atividades ${ }^{11}$.

Segundo Brocka \& Brocka 2 "a comunicação é a cola que solidifica tudo, as técnicas, as práticas, as filosofias e as ferramentas", ou seja uma organização que apresenta um sistema de comunicação ineficiente estará condenando ao fracasso toda e qualquer iniciativa, nos seus mais variados campos de atuação.

Seguindo o pressuposto de Pinho ${ }^{12}$, de que a informação constitui a base do processo decisório, subsidiando 0 planejamento, a execução e a avaliação das ações a serem desenvolvidas, encontrou-se na comunicação escrita uma ferramenta para documentar informações e conhecer melhor a realidade diária dos profissionais da enfermagem. Como Silva ${ }^{13}$, acredita-se que 0 sucesso da passagem de plantão entre os turnos de trabalho na enfermagem depende de um trabalho de equipe bem articulado, criando formas alternativas e eficazes para a transmissão de informações consistentes e de qualidade. Buscou-se aplicar o instrumento em áreas que prestam assistência a pacientes críticos por se acreditar que registrar de forma escrita a dinâmica destas unidades seja uma maneira de buscar melhorá-las de acordo com suas demandas. Além disso, considera-se que, quanto mais crítica for a situação enfrentada, mais importante se torna registrar adequadamente as atividades executadas. As características das unidades, descritas anteriormente, vêm de encontro a essa idéia e permitem uma avaliação criteriosa do instrumento proposto.

\section{CONSIDERAÇÕES FINAIS}

Com base nos resultados obtidos, pode-se concluir que 0 instrumento foi validado quanto ao seu conteúdo por meio da avaliação de juízes, especialistas na área, por não apresentar discordância significativa, demonstrando que o mesmo está adequado quanto a seus conteúdos e permite registrar o que se pretende.

Sua proposta é registrar o panorama diário das unidades onde for aplicado, visando demonstrar e manter registros regulares sobre a dinâmica das unidades, considerando a necessidade de mostrar a rotina e as dificuldades que os profissionais em questão enfrentam para prestar assistência ao paciente.

0 registro escrito sobre o panorama diário destas unidades é de suma importância, pois contribui para o melhor dimensionamento dos recursos e o reconhecimento dos problemas enfrentados para desenvolvimento da assistência aos clientes, tornando-se um documento para negociação com gerentes, serviços de apoio e equipe interdisciplinar, buscando melhorar a rotina diária da unidade.

Um sistema estruturado de registro possibilita 0 planejamento, a avaliação e a negociação nos serviços. Com isso, sugere-se um novo estudo para a aplicação do instrumento validado. 


\section{Referências}

1. Martinelli, MCS. Estudo evolutivo de indicadores hospitalares do Hospital Ana Costa. Qualimetria 1993; 5:4-16.

2. Brocka B, Brocka MS. Gerenciamento da qualidade. São Paulo (SP): Makron do Brasil/ McGrawHill; 1994.

3. Antunes AV. Liderança para a qualidade na enfermagem. Rev Nurs 1999; 5(2): 22- 6.

4. Médici AC. Descentralização e informação em saúde. Plan Polit Publicas 1991; 5: 05-31.

5. Ribeiro M, Santos SL, Meira TGBM. Refletindo sobre liderança em enfermagem. Esc Anna Nery Rev Enferm 2006 abr; 10(1): 109-15.

6. Faria EM. Comunicação e informação: instrumentos para a transformação da prática dos serviços de saúde. Texto \& Contexto Enferm 1995 jan /jun; 4(1): 47-59.

7. Cianciarullo TI. Instrumentos básicos para o cuidar: um desafio para a qualidade de assistência. Rio de Janeiro (RJ): Atheneu; 1996. $154 p$.
8. Nightingale F. Notes on hospitals. Londres (UK): Logman Green; 1863.

9. Donabedian A. The quality of care: how can it be assessed. JAMA 1988; 260: 1743-748.

10. Feigenbaum AV. Controle da qualidade total: gestão e sistemas. São Paulo (SP): Markon; 1994.

11. Mello CHP, et al. ISO 9001-2000: sistemas de gestão da qualidade para operações de produção e serviços. São Paulo (SP): Atlas; 2002.

12. Pinho DLM, Abrahão Jl, Ferreira MC. As estratégias operatórias e a gestão da informação no trabalho de enfermagem, no contexto hospitalar. Rev Latino-am Enfermagem 2003 mar/abr: 11(2): 16875.

13. Silva EE, Campos LF. Passagem de plantão na enfermagem: revisão da literatura. Cogitare Enferm 2007 out/dez; 12 (4): 502-07. 


\section{Apêndice A}

\begin{tabular}{|c|c|c|c|}
\hline \multicolumn{4}{|c|}{ REGISTRO DIÁRIO DA UNIDADE } \\
\hline \multicolumn{3}{|l|}{ 1) Unidade: } & \multirow{2}{*}{\begin{tabular}{|l} 
Data: \\
$\quad$ NOITE
\end{tabular}} \\
\hline 2) Censo & MANHÃ & TARDE & \\
\hline \multicolumn{4}{|l|}{ 2.1) $N^{\circ}$ pacientes início turno } \\
\hline \multicolumn{4}{|l|}{ 2.2) $N^{\circ}$ pacientes final turno } \\
\hline \multicolumn{4}{|l|}{ 2.3) Transferências } \\
\hline \multicolumn{4}{|l|}{ 2.4) Altas } \\
\hline \multicolumn{4}{|l|}{ 2.5) Óbitos } \\
\hline \multicolumn{4}{|l|}{ 2.6) Admissões } \\
\hline \multicolumn{4}{|l|}{ 3) Profissionais de Enfermagem } \\
\hline \multicolumn{4}{|l|}{ 3.1) $N^{\circ}$ Enfermeiros } \\
\hline \multicolumn{4}{|l|}{ 3.2) No Téc. Enf. } \\
\hline \multicolumn{4}{|l|}{ 3.3) $N^{0}$ Aux. Enf. } \\
\hline \multirow{2}{*}{\multicolumn{4}{|c|}{ 3.4) Alunos Enf. }} \\
\hline & & & 4) Procedimentos \\
\hline \multicolumn{4}{|l|}{ 4.1) Banhos realizados } \\
\hline \multicolumn{4}{|l|}{ 4.2) Higiene íntima } \\
\hline \multicolumn{4}{|l|}{ 4.3) Higiene oral } \\
\hline \multicolumn{4}{|l|}{ 4.4) Preparo para exames } \\
\hline \multirow{2}{*}{\multicolumn{4}{|c|}{$\begin{array}{l}\text { 4.5) Passagem de SNE } \\
\text { 4.6) Passagem SNG }\end{array}$}} \\
\hline & & & \\
\hline \multicolumn{4}{|l|}{ 4.7) Passagem SVD / SVA } \\
\hline 4.8) Passagem Uripen & & & \\
\hline 4.9) Punção periférica para acesso & & & \\
\hline 4.10) Coleta gasometria & & & \\
\hline 4.11) Coleta de sangue para exames & & & \\
\hline 4.12) Coleta de material para culturas & & & \\
\hline 4.13) Transporte sem escolta & & & \\
\hline 4.14) RX realizados na unidade & & & \\
\hline 4.15) Curativo de cateter/dreno & 1 & 1 & 1 \\
\hline 4.16) Curativo de Incisão & & & \\
\hline 4.17) Curativo úlcera de pressão & & & \\
\hline 4.18) Curativo de lesão & & & \\
\hline 4.19) Curativo de peritoneostomia & & & \\
\hline 4.20) Higiene osteotraqueal & & & \\
\hline 4.21)Troca fixação cateteres/sondas & 1 & 1 & 1 \\
\hline 4.22$) \mathrm{EOT}$ & & & \\
\hline 4.23) RCP & & & \\
\hline $\begin{array}{l}\text { 4.24) Passagem cateter profundo: } \\
\text { Monolúmem/Duplo lúmen/Shilley }\end{array}$ & & & \\
\hline 4.25$)$ ECG & & & \\
\hline 4.26)Colocar paciente em poltrona & & & \\
\hline 4.27)Retornar paciente ao leito & & & \\
\hline 4.28)Troca de roupa cama & & & \\
\hline 4.29)Outros & & & \\
\hline 5) Perfil Paciente & & & \\
\hline 5.1) Isolamento & & & \\
\hline 5.2) Entubados & & & \\
\hline 5.3) Traqueostomizados & & & \\
\hline 5.4) Ar ambiente & & & \\
\hline 5.5) Ventilação mecânica invasiva & & & \\
\hline 5.6) Ventilação mecânica não-invasiva & & & \\
\hline 5.7) Suporte de 02 & & & \\
\hline 5.8) Sedados & & & \\
\hline
\end{tabular}


5) Perfil Paciente

5.9) $\mathrm{N}^{\circ}$ pacientes em uso droga vasoativa

5.10) Hemodiálise convencional

5.11)Hemolenta

5.12) Irrigação

5.13) Dieta VO assistida

5.14) Nutrição enteral

5.15) Nutrição parenteral

5.16) Mobilização em bloco

5.17) Outros:

\section{6) Pendências}

6.1) Altas não encaminhadas

6.2) Convocar família

6.3) Falta de medicação

6.4) Hemocomponentes ou derivados

6.5) Outros:

\section{7) Intercorrências}

7.1) Falta água/energia

7.2) Problemas rede de gases

7.3) Quebra equipamento: Infusão

b) Cama

c)Outros

7.4) Falta equipamento: a)Sensor 02

b)Esfignomanômetro

c)Estetoscópio

d)Monitor

e)Outros:

7.5) Falta material unidade respiratória

a)Máscara de ambu

b)Umidificador

c)Nebulizador

d)Outro:

7.6) Falta material Central Material Estéril a)Descrição:

7.7) Falta material lavanderia: a) Lençol

b) Fralda pano

c) Fralda descartável

d) Outros:

7.8)Falta material almoxarifado

a)Agulha:

b)Seringa:

c)Luva procedimento

d)Luva estéril

e) Máscara:

d) Tira reagente

e) Outros:

Enfermeiro Responsável / COREn \begin{tabular}{l|l} 
Tarde & Noite \\
\hline
\end{tabular}

\begin{tabular}{|c|c|c|}
\hline Manhã & Tarde & Noite \\
\hline & & \\
\hline & & \\
\hline & & \\
\hline
\end{tabular}

